\title{
Relations of laterality and chewing sidedness in twins
}

\section{Summary}

\section{Objectives}

To study, whether there are associations between chewing side preference and other lateralities, whether there is a genetic origin for preferred chewing side, relations to sex, birth order and orthodontic treatment.

\section{Materials and Methods}

The study included 113 twin pairs, 57 pairs monozygotic, 47 pairs same sex dizygotic and 9 pairs of opposite sex. The lateralities of preferred chewing side, footedness, and eyedness were assessed by functional tests and handedness was checked by asking.

\section{Results}

Right-handed, -footed, and -eyed as separated groups, and true-right sided (combined), were evenly distributed by preferred chewing side. By contrast, left-handed, -footed, -eyed and non-right sided used more left or both sides when chewing. Birth order affected preferred chewing side among monozygotic: The first-born twin was more likely to have the preferred chewing side on the nonright, while second born twins used right side. Gender, zygosity and orthodontic treatment were not statistically significant factors.

\section{Limitations}

Examination of chewing sidedness could have been done in several different ways to provide a definite result. Sample size of opposite sex twins was very small.

\section{Conclusions}

Preferred chewing side generally seemed to follow the side where other lateralities occur; however, monozygotic twins seemed to be more receptive to it. True-right sided were more evenly distributed than non-right sided by the preferred chewing side. 


\section{Abbreviations}

PCS, preferred chewing side; RS, right shift factor; MZ, monozygotic twin; DZ, dizygotic twin; OS, opposite sex twin; TRS, true-right sided (right-handed, -footed and -eyed); NRS, non-right sided, left or indeterminate in some or all of the lateralities (handedness, footedness and eyedness); TMD, temporomandibular disorder; TMJ, temporomandibular joint.

\section{Introduction}

Chewing is a rhythmic masticatory activity, which is controlled by central neural pattern generator which is located in the central nervous system. It is also controlled by the peripheral stimuli, which creates feedback loops, which further regulate the chewing pattern (1). In physiological conditions chewing occurs on both sides but it can occur mainly on the other side (right or left), which is called preferred chewing side (PCS) (2). Current studies have strengthened the impression that most people have a PCS (3). However, this claim is not generally accepted as some results support the view that PCS may not necessarily occur $(4,5)$. According to Barcellos' study $76 \%$ to $87 \%$ of people have a PCS and for the majority the preferred side is right $(3,6)$. These two opinions may be due to differences in the methods used and how the PCS is defined; some authors considered that PCS is the side where the first cycle of chewing occur and some authors considered that the PCS is the side where most of the first cycle of chews or random chews occur $(4,7)$.

There are also divergent opinions about the correlation between PCS and other peripheral lateralities such as handedness, footedness, earedness and eyedness (8). If these lateralities are related, they are probably governed also by the same factors (9). Namely, some studies have discovered the connection between PCS and other lateralities (10,11), while other studies have not (6).

\section{The emergence of lateralities}

The mechanisms that create laterality are still poorly known. The present perception of the origins of asymmetry in anatomy point to the early embryonal chirality of cytoskeletal organizing centers. From this point onwards, speculations differ in how the intracellular chirality is multiplied into cell areas (12). Genetics seem to affect the lateralities: it has been found out that there is a correlation in handedness between parents and their descendant (13). It has been speculated that in the first years of life the infants are influenced by a genetic factor, so-called "right shift factor" (RS+), while 15- 
$20 \%$ of people have a weak or absent manifestation possibly because of a recessive genetic allele (RS-) (14). Some authors think that laterality might be due to partial penetrance (13). It has also been argued that there are two categories of left-sidedness: Those whose genotype is RS- and those whose genotype is RS+ but, because of some environmental or pathological effects, they are left-sided. Twins might be singularly susceptible to those pathological effects (13). In contrast to genetic theories some authors think that only early environmental factors, for example prenatal or perinatal brain hypoxia, may have influence (13). Although monozygotic twins have same DNA and there is evidence about twins mirror imaging (15), studies have shown that there is little difference in cerebral asymmetries between twins of opposite handedness and right-handed twins (16). There is also no difference between twins and single-borns when handedness was concerned; it doesn't seem to depend on hormonal transfer, mirror imaging or twin specific effects (17).

It is also unclear, what is the cause of the PCS. Both peripheral asymmetry and central factors have been suggested (9). On the other hand, also gender and race have been found to affect the PCS $(18,19)$. Among caucasian children more right-side wear was found than in African American children (19). It has also been noticed that females are more symmetric when chewing than males (18).

\section{Central factors}

In functional magnetic resonance imaging (fMRI) during unilateral clenching, it is found that the subjects who have the right PCS and the clenching takes place on the same side, the left primary sensorimotor cortex is significantly more active and the blood's oxygen level increases more than the corresponding regions of the brain from the right side. If the PCS is left and the clenching takes place on the same side, the right sensorimotor cortex is significantly more active than the left side (20). These results suggest that the regions of the brain corresponding to the unilateral chewing are located on the opposite side. Social learning also affects functional lateralities so footedness is a better indicator of cerebral dominance than handedness, although eyedness and earedness seem to be the best indicators $(21,22)$.

\section{Peripheral factors}

The existence of the PCS depends on the consistency and hardness of the food; while eating hard food $74 \%$ of the examinee had a PCS and while eating soft food, only $58 \%$ had the PCS (4). Although some studies have shown that the absence of a tooth does not affect the existence of the PCS (10), it 
has also been found that when chewing unilaterally, the side missing the posterior tooth had worse masticatory performance than the other side, but therefore higher mastication predominance index was found (MPI) (18). In this case, mastication is directed to nonmissing tooth side so the side with better chewing ability is used to compensate for the worse side, therefore making chewing lateral $(23,24)$.

Among the Angle class I $82 \%$ has the right PCS in the first chewing cycle (10). The corresponding percent for the class II is $64 \%$ and for the class III $63 \%$. In the same study it was found that those examinees whose group guidance was to the right, $78 \%$ had the right PCS. For those, who have the canine guidance to the right, $62 \%$ had the right PCS. When the subject had complete and balanced occlusion, $100 \%$ of them had the right PCS.

The laterality of the chewing can be significantly correlated with the earedness, asymmetry of bite force and asymmetry of masticatory performance. On the other hand, the asymmetry of occlusion contact area was weakly related to the PCS and was dependent on the method used (9). Instead, the cusps' form and contact areas in lateral movements seemed to affect the PCS $(25,26)$. Also, the jaw joint and the jaw shape may have an impact on the PCS (27).

\section{Twins}

The comparison of twins can be used to determine whether the functional lateralities are caused by genetic or environmental factors. Twins are either monozygotic (MZ, about 30\% of twin pregnancies) or dizygotic. DZ is due to the fact that two different eggs have been fertilized so they have dichorionic placenta and they can be same sex or opposite sex (OS) twins. MZ are always the same sex but there may exist different types of MZ-twins. The different types are due to timing of egg split, so they have either monochorionic or dichorionic placenta as a consequence of distance between implantation sites. Monoamniotic twins are very rare (28).

The aim of the study was to find out whether the PCS is related to the other lateralities, such as handedness, footedness and eyedness. We compared true-right sided (TRS, hand, foot and eye) to non-right sided (NRS, left or indeterminate in some or all of the lateralities). We were also interested whether there is a genetic origin for the PCS. We'll explore this by examining whether the twins inside of a pair have the same chewing side and compare different twin types (MZ, same sex DZ and 
OS) with each other. We study also whether there is any association between the PCS, gender, twins' birth order and orthodontic treatment.

\section{Materials and Methods}

This study included 113 twin pairs, who were selected to the study on the basis of their willingness to participate in the study from the Lithuanian University of Health Sciences Twin Centre. The approval for the study was obtained from the Kaunas (Lithuania) Regional Biomedical Research Committee (No. BE-2-12). The mean age of the twins was 19.9 years $(\mathrm{SD} \pm 6.5)$, ranging from 8.5 to 45.7. A DNA test was done to determine the zygosity (29). There were 57 pairs of monozygotic twins and 56 pairs of dizygotic twins, out of which 47 were the same sex twin pairs and 9 were the opposite sex twin pairs. The number of male and female pairs was 45 and 59.

The exclusion criteria was: permanent dental extraction, facial trauma, congenital disorders and pregnancy. We also excluded the twins, of whom the necessary information was not determined, such as zygosity, lateralities or sex. The chewing side preference was studied by giving the examinee a gum to chew and by following his or her initiative of chewing for about a minute. Handedness was studied mainly by asking, or if necessary the examinee was asked to write with a pen. When inspecting footedness, examinee was asked to kick a ball and in eyedness, to look in a telescope-like cylinder. If the result was not clear, the test was renewed. If the result was still unclear, it was defined that the examinee used "both sides" and the laterality couldn't be determined. The sample size of people who chewed on both sides was $62(27.4 \%)$.

\section{Statistical analysis}

Relatively simple methods were chosen for statistical testing. Chewing side preference distributions between the zygotes, sexes, TRS and NRS, handedness, footedness, eyedness birth order and those with orthodontic treatment were compared using crosstabs and the significance of distribution differences was measured by the chi-square test. The level of significance for p-value was 0.05 in the statistical tests. Asterisks are used to indicate statistical significance: * means $\mathrm{P} \leq 0.05, * *$ means $\mathrm{P}$ $\leq 0.01$ and $* * *$ means $\mathrm{P} \leq 0.001$. The error bars, $95 \%$ CIs, for the figure were calculated using the following formula: $\mathrm{p}+-1.96 * \sqrt{[}[\mathrm{p} *(1-\mathrm{p}) / \mathrm{n}]$, where $\mathrm{p}$ is percent and $\mathrm{n}$ is sample size. 


\section{Results}

In the study, there were 106 (46.9\%) who preferred the right side and 120 (53.1\%) who preferred the left or both sides while chewing. There was no statistically significant difference in the distribution of the PCS between the twins (MZ, same sex DZ and OS); in all groups about 50\% preferred right side when chewing. Instead, we found out that between sexes, there was a difference in the distribution when comparing all twins as a group, however, it was not statistically significant $(\mathrm{P}=0.283)$. Females were more symmetrical when distributed according to PCS: $50.4 \%$ preferred right. Instead, $57.6 \%$ of males preferred non-right when chewing. When studying twin groups separately, no statistically significant result was found between sexes. However, DZ-twins showed difference in their distribution according to the PCS $(\mathrm{P}=0.067)$. Females preferred right side (58.0\%) and males preferred left $(61.4 \%)$ when chewing.

When comparing PCS to handedness, footedness and eyedness in all twins, we got statistically significant difference in distribution (table 1). Both right-handed and right-footed people were fairly even when they were distributed according to PCS. Almost 50\% of them preferred right side when chewing. Instead, right-eyed people were not so even, though 53.6\% of them had the right PCS. There was a bigger difference in the distribution of PCS in non-right-handed, -footed- and -eyed people. Most of them preferred non-right when chewing (63.6 to $79.3 \%)$.

When comparing preferred chewing side to handedness, footedness and eyedness separately in twin groups (MZ, same sex DZ, OS), we found statistically significant difference $(\mathrm{P}<0.001)$ only in eyedness distribution (supplemental table 1), 57.7\% of right-eyed MZ had right PCS and 76.7\% nonright-eyed MZ had non-right PCS. No similar results were found in same sex DZ or OS.

TRS distributed more evenly than NRS according to PCS in all twins (table 2). 54.8\% of TRS had right PCS, $62.7 \%$ of NRS had non-right PCS. The result was statistically significant. Instead, when considering the distribution separately for different twin groups (MZ, same sex DZ, OS), only MZ had statistically significant differences in PCS distribution $(\mathrm{P}=0.001)$ (supplemental table 2). Figure 1 shows that same sex DZ is clearly more evenly distributed according to PCS. Instead of MZ and OS, whose PCS followed more other lateralities' side. 59.4\% of MZ who were TRS had right PCS. The corresponding percent for OS was 60.0\%. Respectively, 74\% of NRS MZ had non-right PCS, and $62.5 \%$ of NRS OS had non-right PCS. However, for OS, the result was not statistically significant. 
Birth order seemed to affect the PCS (table 3). The first-born twin was more likely to have the PCS on the non-right (56.5 to $69.9 \%$ ), and the second-born twin was more likely to have the PCS on the right (54.3 to $62.5 \%$ ). Even though this was a tendency in all twin groups, statistically significant result was found only in the case of $\mathrm{MZ}(\mathrm{P}=0.002)$. When we studied all twins simultaneously, we received statistically significant result $(\mathrm{P}=0.002)$. Six twins (2 MZ, 2 same sex DZ and 2 OS) didn't have a specified birth order, so table 3 included only 110 twin pairs.

Ongoing or previous orthodontic treatment didn't seem to affect the PCS when compared with people who hadn't got orthodontic treatment (table 4). The distribution in both groups was similar: 45.5 to $47.5 \%$ used right side when chewing and 52.5 to $54.5 \%$ used non-right. 66 people had or had earlier had orthodontic treatment (table 4); 25 of them were undergoing orthodontics and 41 of them had previous orthodontics. $53(80.3 \%)$ of them used removable plate, $7(10.6 \%)$ of them used braces, 5 (7.6\%) of them used both braces and removable plate and one (1.5\%) of them used head gear, QH or other palatal arch and braces.

When comparing the PCS inside each twin pair (twin and co-twin) it resulted that the same PCS (right or non-right) occurred in $49.1 \%$ of the MZ, $48.9 \%$ of the same sex DZ and $44.4 \%$ of the OS (table 5 ) There was no statistically significant difference in distribution. Same kind of comparison were done in handedness, footedness and eyedness with only eyedness showing a significant difference (table 6, supplemental table 3 and 4). In MZ-twins $66.7 \%$ had the same eyedness side like the other twin, unlike the DZ- and OS-twins; $53.2 \%$ and $22.2 \%$ respectively.

\section{Discussion}

Our study found out that the PCS was related with handedness, footedness and eyedness, which is in line with previous findings (10). People who were right-handed, -footed and -eyed, were more evenly distributed by the PCS. However, the greater part of them used right side when chewing (50.5 to $53.6 \%$ ). On the other hand, people who used left or both sides of the peripheral lateralities were more asymmetrically distributed by PCS, the greater part of them used left or both sides when chewing (63.6 to 79.3\%). The PCS, therefore, generally seems to follow the side where other lateralities occur. Because these factors correlate, they are apparently governed by the same factors (9). This finding supports the argument that hemispheric dominance plays a major role in peripheral lateralities, including the PCS. 
It was remarkable, however, that 124 (54.9\%) of the examinee were TRS in the study, but only 54.8\% of them had right PCS. Although the left hemisphere is clearly more dominant than the right one in TRS, still just over a half of them preferred the right side when chewing. We think that this, in turn, supports the argument that the peripheral factors also play an important role in the selection of the PCS.

In previous studies, gender has been found to affect the PCS; females have been found to be more symmetrical than males $(18,19)$. In our study, there were differences in the distribution, but the results were not statistically significant. Females preferred the right side almost as much as non-right but males preferred non-right more (57.6\%). This is in contrast to the Heikkinen's study, which found that African American and Caucasian boys were more right-shifted and lateralized than girls (19,30).

The twins were used here to determine whether the functional lateralities were caused by genetics or environmental factors. We compared whether the PCS of the MZ-, DZ- and OS-twins depends on the PCS of the other twin. The PCS was not significantly dependent of the other twin's PCS. Almost 50\% of the twin pairs had the same PCS and 50\% did not. So, the conclusion is that genetics don't have such a big impact on the PCS. Nonetheless, especially among MZ-twins, eyedness side seemed to depend on the other twin's side. So at least in the case of eyedness, genetics may have an impact. In an earlier study in which handedness was concerned there were no differences in prevalence between zygosity groups or between twins and their singleton siblings (17). But since this genetic issue has been studied only rarely from a genetic point of view, and our study provides more gain for the environmental effects of the PCS, it requires other comparable studies to clarify the problem.

Interesting, however, was the finding that in MZ, both eyedness and distribution to TRS and NRS, have a significant effect on the PCS. Hence, MZ-twins seem to be more receptive to develop a PCS on the same side on which most of their other lateralities are. It is not overruled that these lateralities are anatomically closely interrelated in terms of developmental timing and location.

Ongoing or previous orthodontic treatment didn't seem to affect the PCS. Based on the result that the distribution was even, undergoing orthodontics doesn't cause either right or non-right PCS. Thus, orthodontics doesn't construct unilateral chewing and problems that result from it. Worth noting is that people who have had orthodontic treatment could have been divided less evenly by PCS before undergoing orthodontic treatment. Although these findings and suggestions need other similar studies to be clarified. 
The birth order seems to affect the PCS with all twin groups parallel. A statistically significant result came only in the case of $\mathrm{MZ}$ and when all twins were considered as a group. The first-born twin has more frequently non-right PCS (among MZ-twins 69.6\%) and the second born twin has more frequently right PCS (among MZ-twins 60.7\%). It is unclear, why the order of birth affects the PCS. The results also require more similar studies. In previous studies it has been found that among twins one of whom is right-handed and other is left-handed, there is an association between handedness and birth order: right-handed twin is more likely to have been born first than left-handed (31), opposite effect of birth order in handedness compared to PCS. In the same study, it was also found that corpus callosum is more likely to be bigger among left-handed twins than right-handed. Here the perinatal factors, such as birth start, duration, placental function and effects of reduced oxygen saturation levels should be considered.

Weaknesses of the study are probably concerned with the method of collection of data on lateralities, especially the determination of PCS may be difficult. In addition, the texture of the food affected the PCS; the PCS was more clearly expressed when eating hard food (4), but in our study, we used standardized gum particles. The examinees' consciousness of the study may also affect their actions in the research. Furthermore, the number of OS-twins was so small that it was difficult to acquire statistically significant results when examining twin groups separately, or specific results on the effects of prenatal androgens, which have been monitored in earlier studies, in terms of dental asymmetry (32).

\section{Conclusion for clinicians}

\section{Effects of the PCS}

Tooth-to-tooth occlusal contact caused tooth wear so unilateral chewing caused asymmetric tooth attrition (19,23). Studies have shown that the existence of the PCS affects some structures of the temporomandibular joint (TMJ) even in the asymptomatic patients; joint space was smaller on the preferred side and width of condylar neck of the preferred side was less than that of the unpreferred side or the bilateral TMJ in participants without PCS (27). In addition, unilateral chewing caused asymmetry of the jaw joint dynamics and load distribution $(33,34)$. The PCS has often more contraction capacity than the unpreferred side, but the load of the TMJ was more on the unpreferred side than the preferred side (33-35). In addition to the previous ones, unilateral chewing increases the risk of trauma in the dentition (4). Some studies have found that people who have predominant 
chewing side may have more signs and symptoms of TMD (36,37). However, some of the studies found no connection between PCS and TMD (6).

\section{Occlusal characteristics and orthodontics treatment}

Even though orthodontics don't seem to affect the existence and sidedness of preferred chewing side, orthodontic treatment seems to have same positive effects when unilateral chewing is concerned. For example, in the case of unilateral posterior crossbite, there are more reverse chewing cycles on the crossbite side (38). In this case, orthodontic treatment can cause good final results: after the treatment the reverse chewing cycles decreased and mastication showed a symmetrization between sides (39).

Although orthodontics is usually not the first line treatment of TMD (40), the orthodontic finalization strategy's aim must be functional harmony without one sided chewing habit or falsely related antagonist pairs of teeth (36).

\section{Detection and treatment}

In some cases, for example when restoring missing teeth, preferred chewing side would be good to detect. It can be detected by searching asymmetric tooth wear $(19,23)$ or by giving the examinee a gum and watching which side the examinee uses. When restoring missing teeth on the preferred side it should divide the occlusal load onto more teeth and improve chewing efficiency (10).

\section{Conflict of interest}

There is no conflict of interest among the authors and the manuscript.

\section{Supplementary material}

Supplementary materials are available at European Journal of Orthodontics online.

\section{Acknowledgements}

The collection of the material has been supported by European Orthodontic Society research grant. 


\section{References}

(1) Mohl N, Zarb G, Carlson G, Ruge JD. A Textbook of Occlusion. 1988;10:145-151.

(2) Pond LH, Barghi N, Barnwell GM. Occlusion and chewing side preference. The Journal of prosthetic dentistry 1986;55(4):498-500.

(3) Barcellos DC, de Paiva Gonçalves SE, da Silva MA, Batista GR, Pleffken PR, Pucci CR, et al. Prevalence of chewing side preference in the deciduous, mixed and permanent dentitions. $\mathrm{J}$ Contemp Dental Pract 2011;12(5):339-342.

(4) Zamanlu M, Khamnei S, SalariLak S, Oskoee SS, Shakouri SK, Houshyar Y, et al. Chewing side preference in first and all mastication cycles for hard and soft morsels. Int J Clin Exp Med 2012;5(4):326-331.

(5) Christensen LV, Radue JT. Lateral preference in mastication: a feasibility study. J Oral Rehabil 1985;12(5):421-427.

(6) Martinez-Gomis J, Lujan-Climent M, Palau S, Bizar J, Salsench J, Peraire M. Relationship between chewing side preference and handedness and lateral asymmetry of peripheral factors. Arch Oral Biol 2009;54(2):101-107.

(7) Varela JMF, Castro NB, Biedma BM, Da SD, Quintanilla JS, Muñoz FM, et al. A comparison of the methods used to determine chewing preference. J Oral Rehabil 2003;30(10):990-994.

(8) Barcellos DC, Silva MAD, Batista GR, Pleffken PR, Pucci CR, Borges AB, et al. Absence or weak correlation between chewing side preference and lateralities in primary, mixed and permanent dentition. Arch Oral Biol 2012;57(8):1086-1092.

(9) Rovira-Lastra B, Flores-Orozco EI, Ayuso-Montero R, Peraire M, Martinez-Gomis J.

Peripheral, functional and postural asymmetries related to the preferred chewing side in adults with natural dentition. J Oral Rehabil 2016;43(4):279-285.

(10) Nissan J, Gross M, Shifman A, Tzadok L, Assif D. Chewing side preference as a type of hemispheric laterality. J Oral Rehabil 2004 MAY;31(5):412-416.

(11) Nissan J, Berman O, Gross O, Haim B, Chaushu G. The influence of partial implant-supported restorations on chewing side preference. J Oral Rehabil 2011;38(3):165-169.

(12) Vandenberg LN, Levin M. Far from solved: A perspective on what we know about early mechanisms of left-right asymmetry. Dev Dyn 2010;239(12):3131-3146.

(13) Corballis M. Human laterality. London: Academic press; 1983.

(14) Annett M. The Genetics of Handedness. Trends Neurosci 1981;4(10):256-258.

(15) Sperber GH, Machin GA, Bamforth FJ. Mirror-image dental fusion and discordance in monozygotic twins. Am J Med Genet 1994;51(1):41-45. 
(16) Badzakova-Trajkov G, Häberling IS, Corballis MC. Cerebral asymmetries in monozygotic twins: An fMRI study. Neuropsychologia 2010;48(10):3086-3093.

(17) Medland SE, Duffy DL, Wright MJ, Geffen GM, Hay DA, Levy F, et al. Genetic influences on handedness: Data from 25,732 Australian and Dutch twin families. Neuropsychologia 2009;47(2):330-337.

(18) Heikkinen T, Alvesalo L, Osborne RH, Tienari J, Virtanen J. The Effect of Sex and Race on the Symmetry of the Permanent Tooth Clinical Eruption. International Symposium on Dental Morphology 1998;11:473-482.

(19) Heikkinen T, Rusanen J, Harila V, Alvesalo L. Primary tooth wear in functional literalities. J Dent Child 2009;76(1):5-12.

(20) Jiang H, Liu H, Liu G, Jin Z, Liu X. The effects of chewing-side preference on human brain activity during tooth clenching: An fMRI study. J Oral Rehabil 2010;37(12):877-883.

(21) Hoogmartens MJ, Caubergh MAA. Chewing side preference in man correlated with handedness, footedness, eyedness and earedness. Electromyogr Clin Neurophysiol 1987;27(5):293300 .

(22) Chapman JP, Chapman LJ, Allen JJ. The measurement of foot preference. Neuropsychologia 1987 1987;25(3):579-584.

(23) Iwashita H, Tsukiyama Y, Kori H, Kuwatsuru R, Yamasaki Y, Koyano K. Comparative crosssectional study of masticatory performance and mastication predominance for patients with missing posterior teeth. J Prosthodontic Res 2014;58(4):223-229.

(24) Rovira-Lastra B, Flores-Orozco EI, Salsench J, Peraire M, Martinez-Gomis J. Is the side with the best masticatory performance selected for chewing? Arch Oral Biol 2014;59(12):1316-1320.

(25) Beyron H. Occlusal relation and mastication in Australian Aboriginees. Acta odontologica scandinavica 1964;23:587-678.

(26) Beyron HL. Occlusal changes in adult dentition. Journal of the American Dental Association (1939) 1954;48(6):674-686.

(27) Jiang H, Li C, Wang Z, Cao J, Shi X, Ma J, et al. Assessment of osseous morphology of temporomandibular joint in asymptomatic participants with chewing-side preference. J Oral Rehabil 2015;42(2):105-112.

(28) Nikkels PGJ, Hack KEA, van Gemert MJC. Pathology of twin placentas with special attention to monochorionic twin placentas. J Clin Pathol 2008 DEC;61(12):1247-1253.

(29) Vuollo V, Sidlauskas M, Sidlauskas A, Harila V, Salomskiene L, Zhurov A, et al. Comparing facial 3D analysis with DNA testing to determine zygosities of twins. Twin Res Hum Genet 2015;18(3):306-313.

(30) Heikkinen T, Alvesalo L, Osborne RH, Tienari J. Tooth eruption symmetry in functional lateralities. Arch Oral Biol 2001;46(7):609-617. 
(31) Gurd JM, Cowell PE, Lux S, Rezai R, Cherkas L, Ebers GC. FMRI and corpus callosum relationships in monozygotic twins discordant for handedness. Brain Structure and Function 2013;218(2):491-509.

(32) Heikkinen T, Harila V, Ollikkala A, Alvesalo L. Primary tooth size asymmetry in twins and singletons. Orthodont Craniofac Res 2016;19(3):145-153.

(33) Miyowaki S, Tanimoto Y, Kawakami T, Sugimura M, Takano-Yamamoto T. Motion of the human mandibular condyle during mastication. J Dent Res 2001;80(2):437-442.

(34) Pérez Del Palomar A, Santana-Penín U, Mora-Bermúdez MJ, Doblaré M. Clenching TMJsloads increases in partial edentates: A 3D finite element study. Ann Biomed Eng 2008;36(6):10141023.

(35) Ono T, Hasegawa Y, Hori K, Nokubi T, Hamasaki T. Task-induced activation and hemispheric dominance in cerebral circulation during gum chewing. J Neurol 2007;254(10):1427-1432.

(36) Reinhardt R, Tremel T, Wehrbein H, Reinhardt W. The unilateral chewing phenomenon, occlusion, and TMD. Cranio 2006;24(3):166-170.

(37) Santana-Mora U, López-Cedrún J, Mora MJ, Otero XL, Santana-Penín U. Temporomandibular Disorders: The Habitual Chewing Side Syndrome. PLoS ONE 2013;8(4).

(38) Brin I, Ben-Bassat Y, Blustein Y, Ehrlich J, Hochman N, Marmary Y, et al. Skeletal and functional effects of treatment for unilateral posterior crossbite. Am J Orthod Dentofacial Orthop 1996;109(2):173-179.

(39) Piancino MG, Falla D, Merlo A, Vallelonga T, de Biase C, Dalessandri D, et al. Effects of therapy on masseter activity and chewing kinematics in patients with unilateral posterior crossbite. Arch Oral Biol 2016 JUL;67:61-67.

(40) Proffit WM, Fields HW, Sarver DM. Contemporary orthodontics. 5th ed.: Elsevier; 2013. 
Table 1. Handedness, footedness and eyedness distributed according to preferred chewing side.

\begin{tabular}{|c|c|c|c|c|c|c|}
\hline \multirow[b]{2}{*}{$\begin{array}{l}\text { Preferred } \\
\text { chewing } \\
\text { side }\end{array}$} & \multicolumn{2}{|c|}{ Handedness } & \multicolumn{2}{|l|}{ Footedness } & \multicolumn{2}{|l|}{ Eyedness } \\
\hline & $\begin{array}{l}\text { Right } \\
\text { n (\%) }\end{array}$ & $\begin{array}{l}\text { Non-right } \\
\mathrm{n}(\%)\end{array}$ & $\begin{array}{l}\text { Right } \\
\text { n (\%) }\end{array}$ & $\begin{array}{l}\text { Non-right } \\
\text { n (\%) }\end{array}$ & $\begin{array}{l}\text { Right } \\
\text { n (\%) }\end{array}$ & $\begin{array}{l}\text { Non-right } \\
\text { n }(\%)\end{array}$ \\
\hline Right & $\begin{array}{l}100 \\
(50.8)\end{array}$ & $6(20.7)$ & $98(50.5)$ & $8(25.0)$ & $74(53.6)$ & $32(36.4)$ \\
\hline Non-right & $97(49.2)$ & $23(79.3)$ & $96(49.5)$ & $24(75.0)$ & $64(46.4)$ & $56(63.6)$ \\
\hline Total & $\begin{array}{l}197 \\
(100)\end{array}$ & $29(100)$ & $194(100)$ & $32(100)$ & $138(100)$ & $88(100)$ \\
\hline P-value & $0.003 * *$ & & $0.008 * *$ & & $0.014 *$ & \\
\hline
\end{tabular}


Supplemental table 1. Handedness, footedness and eyedness distributed according to preferred chewing side by the zygosities.

\begin{tabular}{|c|c|c|c|c|c|c|c|}
\hline \multirow[b]{2}{*}{ Zygosity } & \multirow[b]{2}{*}{$\begin{array}{l}\text { Preferred } \\
\text { chewing } \\
\text { side }\end{array}$} & \multicolumn{2}{|c|}{ Handedness } & \multicolumn{2}{|c|}{ Footedness } & \multicolumn{2}{|l|}{ Eyedness } \\
\hline & & $\begin{array}{l}\text { Right } \\
\text { n (\%) }\end{array}$ & $\begin{array}{l}\text { Non-right } \\
\mathrm{n}(\%)\end{array}$ & $\begin{array}{l}\text { Right } \\
\text { n (\%) }\end{array}$ & $\begin{array}{l}\text { Non-right } \\
\mathrm{n}(\%)\end{array}$ & $\begin{array}{l}\text { Right } \\
\text { n (\%) }\end{array}$ & $\begin{array}{l}\text { Non-right } \\
\mathrm{n}(\%)\end{array}$ \\
\hline \multirow[t]{2}{*}{$\mathrm{MZ}$} & Right & $\begin{array}{l}48 \\
(48.0)\end{array}$ & $3(21.4)$ & $\begin{array}{l}46 \\
(48.4)\end{array}$ & $5(26.3)$ & $\begin{array}{l}41 \\
(57.7)\end{array}$ & $10(23.3)$ \\
\hline & Non-right & $\begin{array}{l}52 \\
(52.0)\end{array}$ & $11(78.6)$ & $\begin{array}{l}49 \\
(51.6)\end{array}$ & $14(73.7)$ & $\begin{array}{l}30 \\
(42.3)\end{array}$ & $33(76.7)$ \\
\hline P-value & & 0.085 & & 0.128 & & $<0.001 * *$ & \\
\hline \multirow[t]{2}{*}{ Same sex DZ } & Right & $\begin{array}{l}43 \\
(53.1)\end{array}$ & $3(23.1)$ & $\begin{array}{l}44 \\
(52.4)\end{array}$ & $2(20.0)$ & $\begin{array}{l}26 \\
(46.4)\end{array}$ & $20(52.6)$ \\
\hline & Non-right & $\begin{array}{l}38 \\
(46.9)\end{array}$ & $10(76.9)$ & $\begin{array}{l}40 \\
(47.6)\end{array}$ & $8(80.0)$ & $\begin{array}{l}30 \\
(53.6)\end{array}$ & $18(47.4)$ \\
\hline P-value & & 0.071 & & 0.091 & & 0.675 & \\
\hline \multirow[t]{2}{*}{ OS } & Right & $\begin{array}{l}9 \\
(56.3)\end{array}$ & $0(0.0)$ & $8(53.3)$ & $1(33.3)$ & 7 (63.6) & $2(28.6)$ \\
\hline & Non-right & $\begin{array}{l}7 \\
(43.8)\end{array}$ & $2(100.0)$ & $7(46.7)$ & $2(66.7)$ & $4(36.4)$ & $5(71.4)$ \\
\hline P-value & & 0.471 & & 1.000 & & 0.335 & \\
\hline
\end{tabular}

Table 2. True right-sided and non-right-sided distributed according to preferred chewing side.

\begin{tabular}{lll}
\hline \multirow{2}{*}{ Preferred chewing side } & \multicolumn{2}{l}{ Handedness, footedness and eyedness } \\
\cline { 2 - 3 } & $\mathrm{TRS}$ & $\mathrm{NRS}$ \\
& $\mathrm{n}(\%)$ & $\mathrm{n}(\%)$ \\
\hline Right & $68(54.8)$ & $38(37.3)$ \\
Non-right & $56(45.2)$ & $64(62.7)$ \\
Total & $124(100)$ & $102(100)$ \\
P-value & $0.011^{*}$ & \\
\hline
\end{tabular}


Supplemental table 2. TRS and NRS distributed according to PCS by the zygosities.

\begin{tabular}{|c|c|c|c|}
\hline & \multirow[b]{2}{*}{$\begin{array}{l}\text { Preferred } \\
\text { side }\end{array}$} & \multicolumn{2}{|c|}{ True right-sided or nonright-sided } \\
\hline & & $\begin{array}{l}\text { TRS } \\
\mathrm{n}(\%)\end{array}$ & $\begin{array}{l}\text { NRS } \\
\text { n (\%) }\end{array}$ \\
\hline \multirow[t]{3}{*}{$\mathrm{MZ}$} & Right & $38(59.4)$ & $13(26.0)$ \\
\hline & Nonright & $26(40.6)$ & $37(74.0)$ \\
\hline & P-value & $0.001 * * *$ & \\
\hline \multirow[t]{3}{*}{$\mathrm{DZ}$} & Right & $24(48.0)$ & $22(50.0)$ \\
\hline & Nonright & $26(52.0)$ & $22(50.0)$ \\
\hline & P-value & 1.000 & \\
\hline \multirow[t]{3}{*}{ OS } & Right & $6(60.0)$ & $4(37.5)$ \\
\hline & Nonright & $4(40.0)$ & $5(62.5)$ \\
\hline & P-value & 0.637 & \\
\hline
\end{tabular}

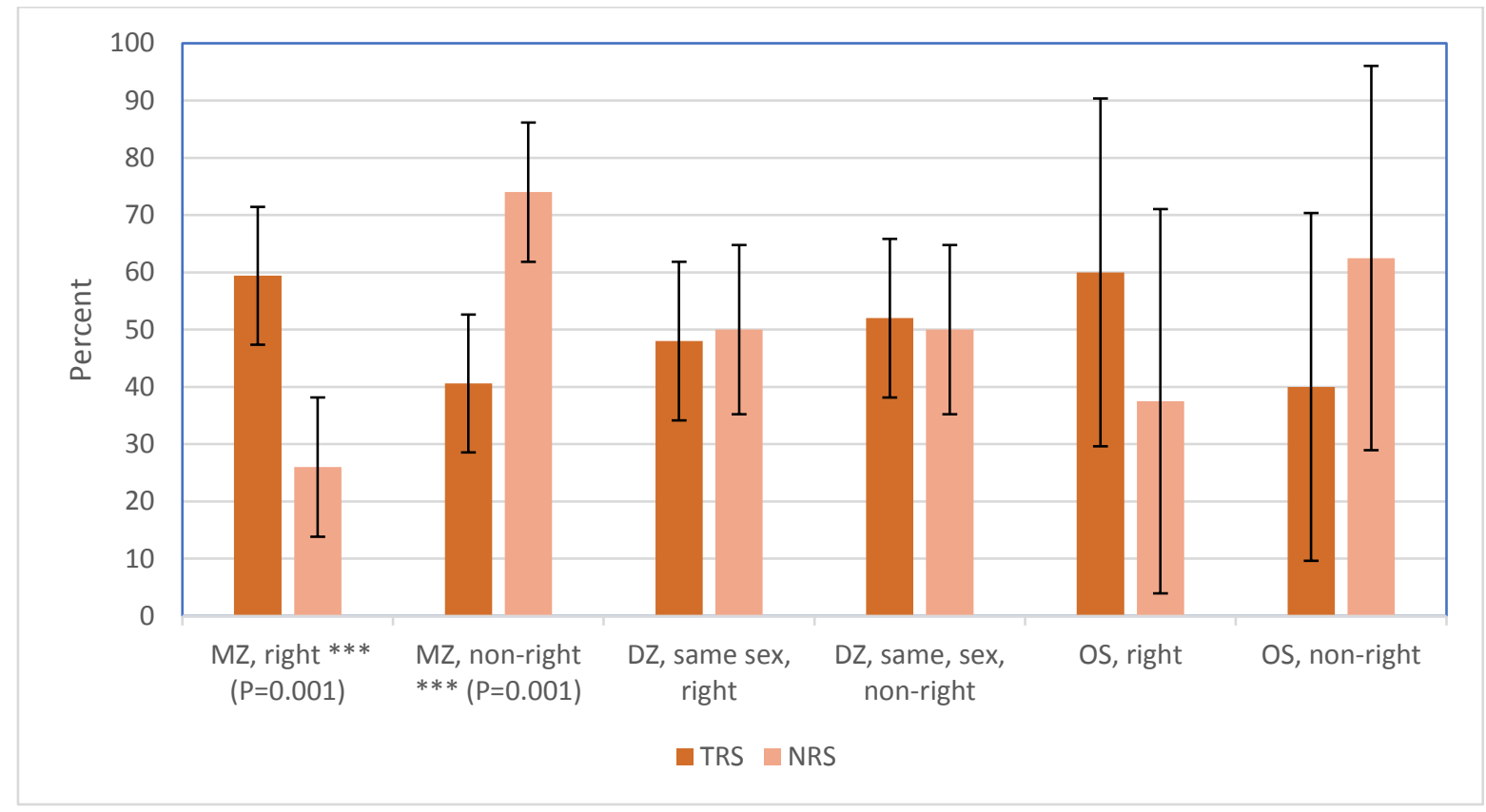

Figure 1. Preferred chewing side's (right or non-right) distribution according to TRS and NRS among MZ, same sex DZ and OS with error bars, 95\% CIs. 
Table 3. The effect of the birth order on the distribution of preferred chewing side by the zygosities.

\begin{tabular}{lllll}
\hline \multirow{2}{*}{ Zygosity } & Preferred chewing & \multicolumn{2}{l}{ Birth order } & \\
\cline { 3 - 4 } & side & The first & The second & P-value \\
& Right & $17(30)$ & $\mathrm{n}(\%)$ & \\
\hline MZ & Non-right & $39(69.6)$ & $22(39.3)$ & $0.002 * *$ \\
& Right & $20(43.5)$ & $25(54.3)$ & 0.404 \\
DZ & Non-right & $26(56.5)$ & $21(45.7)$ & \\
OS & Right & $3(37.5)$ & $5(62.5)$ & 0.619 \\
& Non-right & $5(62.5)$ & $3(37.5)$ & \\
All twins & Right & $40(36.4)$ & $64(58.2)$ & $0.002 * *$ \\
& Non-right & $70(63.6)$ & $46(41.8)$ & \\
\hline
\end{tabular}

Table 4. The effect of the undergoing or previous orthodontic treatment on distribution of preferred chewing side.

\begin{tabular}{lll}
\hline & \multicolumn{2}{l}{ Undergoing or previous orthodontic treatment } \\
\cline { 2 - 3 } Preferred chewing side & Yes & No \\
& $\mathrm{n}(\%)$ & $\mathrm{n}(\%)$ \\
\hline Right & $30(45.5)$ & $76(47.5)$ \\
Non-right & $36(54.5)$ & $84(52.5)$ \\
Total & $66(100)$ & $160(100)$ \\
P-value & 0.884 & \\
\hline
\end{tabular}

Table 5. Zygosities distributed according to whether the twin pairs have same PCS or not.

\begin{tabular}{lllll}
\hline & \multicolumn{2}{l}{ Zygosity } & \\
\cline { 2 - 4 } PCS between & $\mathrm{MZ}$ & same sex DZ & OS & Total \\
twin pairs & $\mathrm{n}(\%)$ & $\mathrm{n}(\%)$ & $\mathrm{n}(\%)$ & $\mathrm{n}(\%)$ \\
\hline The same side & $56(49.1)$ & $46(48.9)$ & $8(44.4)$ & $110(48.7)$ \\
The other side & $58(50.9)$ & $48(51.1)$ & $10(55.6)$ & $116(51.3)$ \\
P-value & $0.958(1.000$ if OS-twins were excluded) & \\
\hline
\end{tabular}


Table 6. Zygosities distributed according to whether the twin pairs have the same eyedness' side or not.

\begin{tabular}{lllll}
\hline \multirow{2}{*}{$\begin{array}{l}\text { Eyedness between } \\
\text { twin pairs }\end{array}$} & $\mathrm{n}(\%)$ & same sex DZ & $\mathrm{OS}$ & Total \\
\cline { 2 - 4 } & $\mathrm{MZ}$ & $\mathrm{n}(\%)$ & $\mathrm{n}(\%)$ & $\mathrm{n}(\%)$ \\
\hline The same side & $76(66.7)$ & $50(53.2)$ & $4(22.2)$ & $130(57.5)$ \\
The other side & $38(33.3)$ & $44(46.8)$ & $14(77.8)$ & $96(42.5)$ \\
P-value & $0.001 * * *(0.064$ if OS-twins were excluded $)$ & \\
\hline
\end{tabular}

Supplemental table 3. Zygosities distributed according to whether the twin pairs have the same handedness' side or not.

\begin{tabular}{lllll}
\hline & \multicolumn{2}{l}{ Zygosity } & \\
\cline { 2 - 4 } Handedness & $\mathrm{MZ}$ & same sex DZ & $\mathrm{OS}$ & Total \\
between twin pairs & $\mathrm{n}(\%)$ & $\mathrm{n}(\%)$ & $\mathrm{n}(\%)$ & $\mathrm{n}(\%)$ \\
\hline The same side & $98(86.0)$ & $72(76.6)$ & $14(77.8)$ & $184(81.4)$ \\
The other side & $16(14.0)$ & $22(23.4)$ & $4(22.2)$ & $42(18.6)$ \\
P-value & $0.197(0.104$ if OS-twins were excluded) & \\
\hline
\end{tabular}

Supplemental table 4. Zygosities distributed according to whether the twin pairs have the same footedness' side or not.

\begin{tabular}{lllll}
\hline \multirow{2}{*}{$\begin{array}{l}\text { Footedness } \\
\text { between twin pairs }\end{array}$} & $\mathrm{n}(\%)$ & same sex DZ & $\mathrm{OS}$ & Total \\
\cline { 2 - 5 } & $\mathrm{MZ}$ & $\mathrm{n}(\%)$ & $\mathrm{n}(\%)$ & $\mathrm{n}(\%)$ \\
\hline The same side & $92(80.7)$ & $74(78.7)$ & $12(66.7)$ & $178(78.8)$ \\
The other side & $22(19.3)$ & $20(21.3)$ & $6(33.6)$ & $48(21.2)$ \\
P-value & $0.393(0.732$ if $)$ & \\
\hline
\end{tabular}

